\title{
Effects of Nutrient Enrichment on the Stability of Producer Species Under the Pressure of Predation
}

\author{
Fang Zhao ${ }^{1, a}$,Huayong Zhang ${ }^{1, b,{ }^{*}}$, Lei Zhao ${ }^{1, c}$ and Wang Tian ${ }^{1, d}$ \\ ${ }^{1}$ Research Center for Engineering Ecology and Nonlinear Science, North China Electric Power \\ University, Beijing 102206, P.R. China \\ am18634964488@163.com,,rceens@ncepu.edu.cn,'haolei@ncepu.edu.cn, ${ }^{\mathrm{d}}$ tianwang870822@16 \\ 3.com, ${ }^{*}$ corresponding author
}

\begin{abstract}
Keywords:nutrient enrichment, population dynamics, stability, generalist predation.
Abstract. Nutrient enrichment has a great influence on the stability of producer species. However, in the presence of predators, its influence has not yet been studied. In this research, we build a food web model which coupled a classic nutrient competition model with a bio-energetic predator-prey model, and a trade-off between competitive abilities of producers is considered.We considered the generalist predation and explored the effect of nutrient enrichment on the stability of producer species under the pressure of predation. The results showed increasing with the nutrient supplement, the biomass of the producers increased and the stability of producer was broken. It turned out that eutrophication destroyed the stability of producer species. Results in this research will be helpful in understanding the influence of nutrient enrichment under the pressure of predation and providing theoretical guidance for ecosystem and biodiversity conservation.
\end{abstract}

\section{Introduction}

The stability of producer species is important in maintaining the functions of an ecosystem. Nutrient enrichment by human activities is one of the greatest threats to global ecosystems and it has great influence on the stability of producer species [1]. As a result, species extinction or even breakdown of ecosystem is often happen. Knowing the effects of nutrient enrichment is an important and wide discussed subject in both theoretical and applied ecology [2].

Ecologists have researched the influence of nutrient enrichment on stability of producers for a long time. Early in 1971, Rosenzweig demonstrated that with the increase of resource supply, species abundance will oscillate more intensively, the minimum values of the population abundance decrease and finally drop below a local extinction threshold [3]. This so called 'paradox of enrichment' is analyzed in a simple consumer-resource model [3-6]. Then many ecologists tried to test this idea through theoretical and experimental approach. For example, Simple models of predator-prey dynamics predict a "paradox of enrichment", where enriching the prey causes population cycles that increase in amplitude with further enrichment [3,7-9]. In a classic laboratory experiment conducted by Huffaker et al. (1963), increasing the supply of food to herbivorous mites destabilized their interaction with predatory mites and resulted in the extinction of both species. The dynamics of a protozoan predator-prey system was also destabilized by enriching the prey [10]. However, these analyses are based on two trophic levels. The influence of nutrient enrichment on the stability of producer species under the pressure of predation has not been analyzed.

In this research, the food web model is constructed by adding two specialist consumer species to a well-known resource competition model [11-13], in which two producer species are competing for two essential nutrients. A bio-energetic model with allometric coefficients [8,17-21] is employed to depict the producer-consumer interactions, and then we added a generalist predator into the system. The influences of nutrient enrichment on the stability of producer species in this model are examined via analyzing the standard deviation of the producer species. Through theoretical analysis, the results show that with generalist predation nutrient enrichment destroys the stability of producer species, which provide a theoretical support to protect the diversity of species under the condition of eutrophication. 


\section{Methods}

The Model.The food web model is constructed by two producer species competing for two limiting nutrients, and a generalist predator. In the research, the effects of nutrient enrichment are analyzed following two scenarios: 1) the supply concentration of nutrient 1 increase linearly while the concentration of nutrient 2 keeps constant; 2) the supply concentration of nutrient 1 increases and the concentration of nutrient 2 decreases, while the total amount of these two nutrients remains constant. Thestandard deviationof producers' abundance in the food web is analyzed to explore the stability of producers under nutrient enrichment.

The food web model is given as follows:

$$
\begin{aligned}
& \frac{d N_{j}}{d t}=D\left(S_{j}-N_{j}\right)-\sum_{i=1}^{2} c_{j i} \mu_{i}\left(N_{1}, N_{2}\right) P_{i} j=1,2(1 \mathrm{a}) \\
& \frac{d P_{i}}{d t}=P_{i}\left[\mu_{i}\left(N_{1}, N_{2}\right)-x_{P_{i}}\right]-x_{C i} y_{i} f_{i}\left(P_{i}\right) C_{i} / e_{i}^{i}=1,2(1 \mathrm{~b}) \\
& \frac{d C_{i}}{d t}=x_{C i} y_{i} f_{i}\left(P_{i}\right) C_{i}-x_{C i} C_{i} i=1,2(1 \mathrm{c})
\end{aligned}
$$

Here $N_{j}$ denotes the abundance of nutrient $j, P_{i}$ denotes the biomass of producer $i$, and $C_{i}$ denotes the biomass of consumer $i$ which only feeds on producer $i$.

In the Equation (1a) $D$ is the system's turnover rate; $S_{j}$ is the supply concentration of nutrient $j, c_{j i}$ is the content of resource $j$ in species $i$. We assume that the specific growth rates follow the Monod equation:

$$
\mu_{i}\left(N_{1}, N_{2}\right)=\min \left(\frac{r_{i} N_{1}}{K_{1 i}+N_{1}}, \frac{r_{i} N_{2}}{K_{2 i}+N_{2}}\right)(2)
$$

where $r_{i}$ is the maximum specific growth rate of species $i, K_{j i}$ is the half-saturation constant for resource $j$ of species $i$, and the 'min' refers to the minimum function.

In the Equation (1b) $x_{P i}$ and $x_{C i}$ denote the mass-specific metabolic rate of producer $i$ and consumer $i$ respectively; $y_{i}$ is the maximum consumption rate of consumer $i$ relative to its metabolic rate; $e_{i}$ is the biomass conversion efficiency of the consumer $i$ ingesting producer $i$.

Equation (1c) is the time derivative of the consumers' biomasses. Here the functional response $f_{i}$ describes the realized fraction of the consumer's maximum rate of consumption:

$$
f_{i}\left(P_{i}\right)=\frac{P_{i}}{K_{C i}+P_{i}}(3)
$$

where $K_{C i}$ is the half saturation density. This response is the Holling type II response [22],also it is the widely used functional response.

Parameters. The reference parameter values for the nutrient-producer interactions have already been used by Huisman and other authors $[11,12,14-16]$. According to the references, $D=0.25$ day $^{-1}$ is employed here for all nutrients, and $r_{i}=1 \mathrm{day}^{-1}$ for all producers. The values of $K$ and $c$ are given in the matrixes below:

$$
K=\left[\begin{array}{ll}
0.15 & 0.1 \\
0.1 & 0.2
\end{array}\right] C=\left[\begin{array}{ll}
1.0 & 0.5 \\
0.5 & 1.0
\end{array}\right]
$$

Different columns represent different consumers, and different rows represent different resources. $y=6, e_{i}=0.45$ and $K_{C i}=0.5[8,20,21,23]$. The metabolic rate is calculated as below:

$$
x=\frac{a_{x}}{a_{r}}\left[L^{0.25}\right]^{l-1}
$$

where $a_{x} / a_{r}$ is 0.138 for producers and 0.314 for consumers $[2,17,19,24], l$ is the species' trophic level and $L$ is producer-consumer body size ratio selected as 0.1 here [21]. $x_{P i}$ and $x_{C i}$ are calculated to be 0.138 and 0.162 respectively. 


\section{Results}

Fig. 1 shows the stability of the two producer species with one generalist predator under different nutrients supply. Through the figure we can conclude that under low concentration of nutrients 1 and 2, the standard deviation of the two producer species is zero, since the producer species can not survive under the pressure of low nutrients and predation. This is a stable point of the system but with less ecological significance. Then with the increase of nutrient concentration, the standard deviation of the two producer species is increasing and the stability of the two producer species is decreasing. When the nutrients supply is sufficient, the standard deviation of the two producer species changed slowly. These kinds of phenomenon can be seen through both 3D and contour figures.

(a)

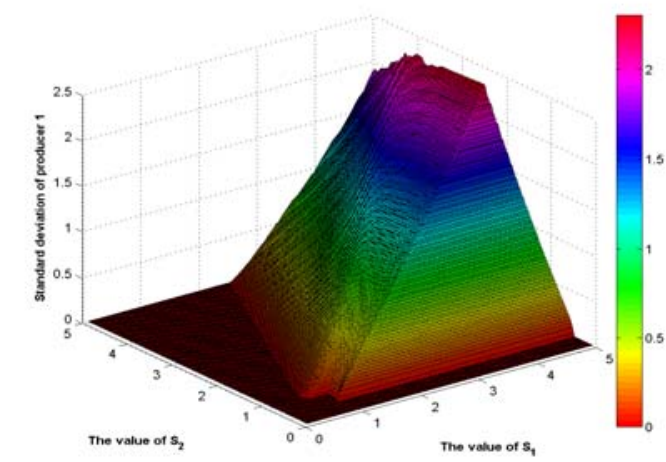

(c)

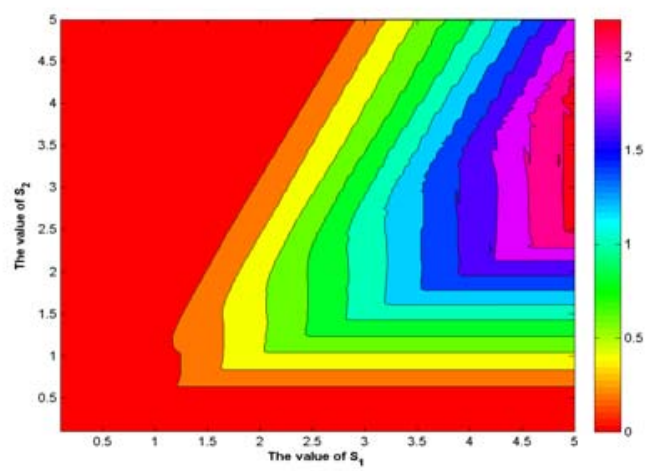

(b)

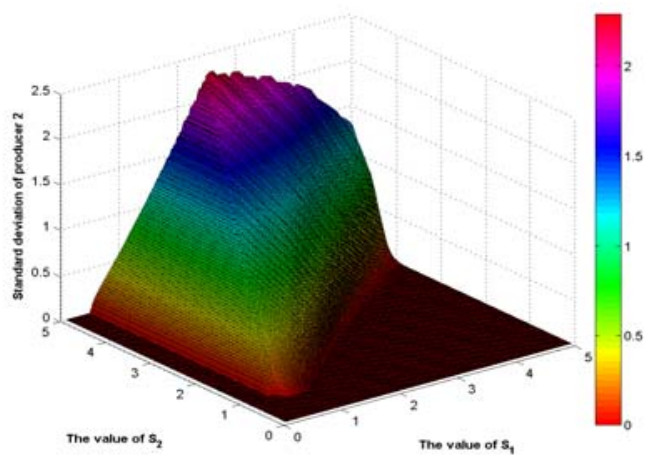

(d)

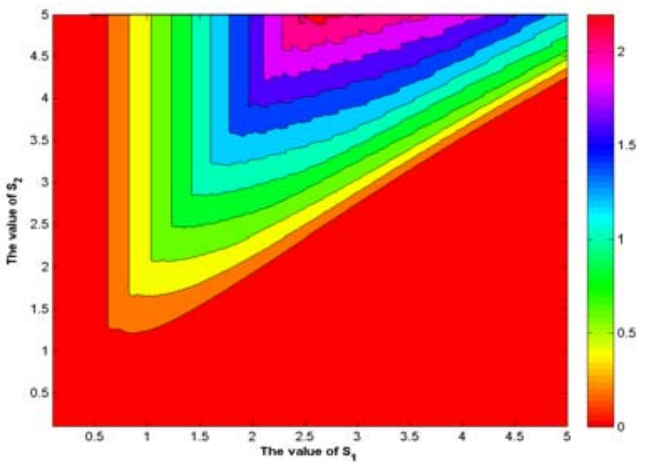

Fig. 1.Standard deviation of the two producer species in the food web with generalist predation. (a) and (b) are 3D figures of producer 1 and producer 2, while (c) and (d) are contour figures of producer 1 and producer 2 .

To analyze the stability of producers under generalist predation further, the bifurcation diagram (fig. 2a and 2c) and the mean biomass (fig. 2b and 2d) of producer species have been researched along the supplement of nutrient 1 in two scenarios. In scenario 1 S2 keeps constant at 2, while in scenario 2 the sum of S1 and S2 remains at 4.

In the upper left zone, nutrient 1 is the limiting resource, thus producer 2 , which is the better competitor for nutrient 1 , will win the competition and exclude producer 1 . With the increasing of supplement of nutrient 1 , at first the producer biomass is too little to sustain the predator and the biomass of producer 2 keeps rising. When the producer biomass is big enough, the predator population can survive. Meanwhile, the flows of increasing nutrients move along the food chain to the upper trophic level, which causing the producer biomass keeps constant. This is completely coherent with the 'trophic cascade' theory $[25,26]$. After that, the population of producer 2 begins to oscillate, with the amplitude and mean value increasing with the nutrient supplement, and the 'enrichment paradox’ emerges [3]. 
(a)

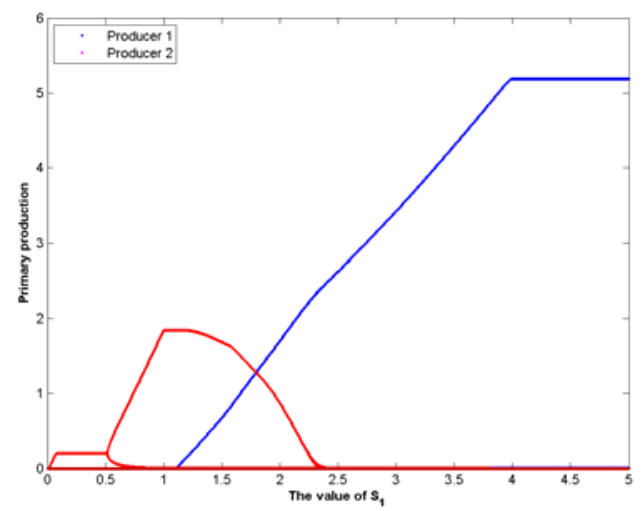

(c)

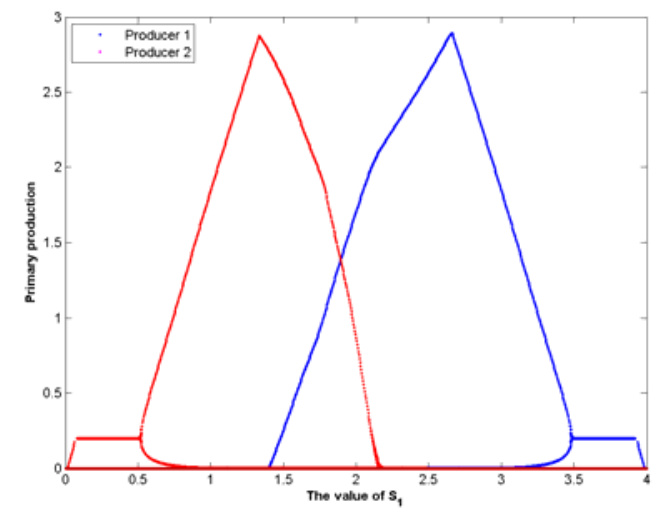

(b)

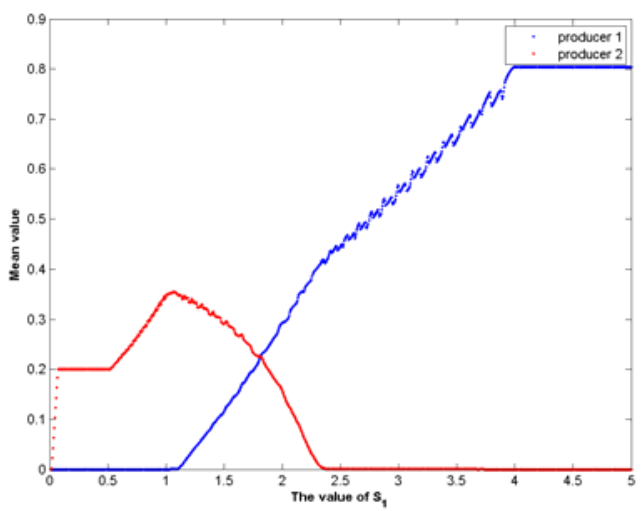

(d)

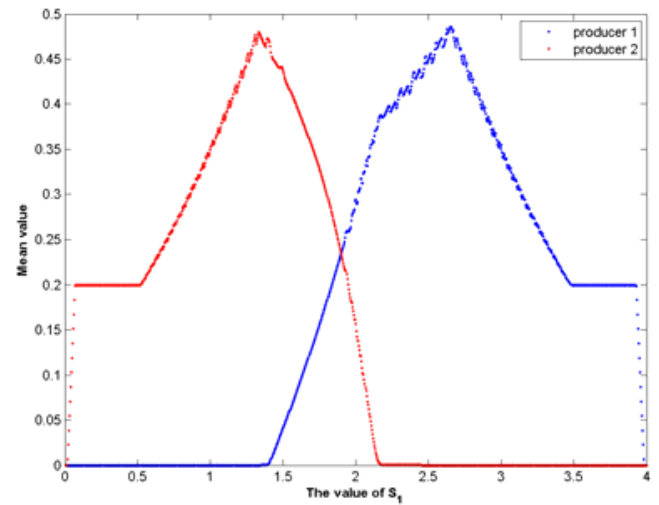

Fig. 2. Bifurcation diagram (plotting the local maximum and minimum values during the time series at each supplement) and mean biomass of producer species in scenario 1 (a and b) and scenario 2 (c and d) with generalist predation. Blue points indicate biomass of producer 1 while red ones indicate producer 2. In scenario $1 \mathrm{~S} 2$ keep constant while in scenario 2 the sum of $S_{1}$ and $S_{2}$ keeps constant. The mean biomasses and bifurcation diagrams are calculated and plotted for the period from 1000 to 2000 days to avoid initial influences.

In the middle zone, both of the two nutrients are the limiting resources and the two producer species can coexist because 'each species consumes most of the resource for which it has the highest requirement' [13] and the predator species give the same top-down pressure to these two producer species.This is the process of the old winner being replaced gradually by the new dominators because of the changing of the nutrient supplements. This is coherent with the ordinary attitude that generalist predation imposes apparent competition [27] between prey species.

In the lower right zone, nutrient 2 is the limiting resource and producer 1 is the better competitor of nutrient 2 and will win the competition. In scenario 1 the primary biomass keeps constant because the growth of producer 2 is limited by nutrient 2 . In scenario 2 , things are nearly the same as those in the upper left zone, except that the leading actor is producer 2.

\section{Conclusions}

In this work, we explored the responses of the stability of producer species to the nutrient enrichment with a generalist consumer.Generalist predators impose apparent competition and eventually lead to competitive exclusion. We found that the biomass of the producer increases with enriched nutrient concentrations, and the stability of producer species is broken.

\section{Acknowledgements}

This work was supported by the National Science and Technology Support Project (2006BAC10B0 
3) and the National Water Special Project (No. 2009ZX07210-009, No. 2015ZX07203-011, No. 20 15ZX07204-007) and Ecological Safety Survey and Assessment of Nansi Lake (2012-2015) and Ec ological Riverway Artificial Strengthen Key Technology Research and Demonstration Project of Sh andong Province (SDHBPJ-ZB-08).

\section{References:}

[1] Davis J.M., Rosemond A.D., Eggert S.L., Cross W.F. \& Wallace J.B., Long-term nutrient enrichment decouples predator and prey production. Proceedings of the National Academy of Sciences.107, 121-126 (2010).

[2] Rall BC,Guill C, Brose U., Food-web connectance and predator interference dampen the paradox of enrichment.Oikos.117, 202-213 (2008).

[3] Rosenzweig ML, Paradox of Enrichment: Destabilization of Exploitation Ecosystems in Ecological Time.Science.171, 385-387 (1971).

[4] Rosenzweig ML, Schaffer WM.Homage to the red queen. II. Coevolutionary response to enrichment of exploitation ecosystems.TheorPopul Biol. 14, 158-163 (1978).

[5]Genkai-KatoM,Yamamura N.Unpalatable prey resolves the paradox of enrichment.Proceedings of the Royal Society B: Biological Sciences.266, 1215 (1999).

[6] Boukal DS, Sabelis MW, Berec L. How predator functional responses and Allee effects in prey affect the paradox of enrichment and population collapses.TheorPopul Biol. 72, 136-147(2007).

[7] Gilpin, M.E. Enriched predator-prey systems: theoretical stability. Science.177,902-904 (1972).

[8] Yodzis, P., and S. Innes. Body size and consumer resource dynamics.American Naturalist 139,1151-1175 (1992).

[9] Abrams, P. A., and J. Roth. The responses of unstable food chains to enrichment.Evolutionary Ecology.8,150-171 (1994).

[10] Luckinbill, L. S. The effects of space and enrichment on a predator-prey system.Ecology.55,1142-1147 (1974).

[11]Huisman J. \&Weissing F.J. Biodiversity of plankton by species oscillations and chaos.Nature. 402,407-410 (1999).

[12]Huisman J. \&Weissing F.J. Fundamental Unpredictability in Multispecies Competition. The American Naturalist. 157, 488-494 (2001a).

[13]Huisman J. \&Weissing F.J. Biological Conditions for Oscillations and Chaos Generated by Multispecies Competition. Ecology.82, 2682-2695 (2001b).

[14]Huisman J., Johansson A.M., Folmer E.O. \&Weissing F.J. Towards a solution of the plankton paradox: the importance of physiology and life history. EcolLett.4, 408-411(2001).

[15]Scheffer M., Rinaldi S., Huisman J. \&Weissing F.J.Why plankton communities have no equilibrium: solutions to the paradox. Hydrobiologia, 9-18(2003).

[16]Roelke D., Augustine S. \&Buyukates Y. Fundamental Predictability in Multispecies Competition: The Influence of Large Disturbance. The American Naturalist.162, 615-623(2003).

[17]Brose U., Ostling A., Harrison K. \& Martinez N.D. Unified spatial scaling of species and their trophic interactions.Nature.428, 167-171 (2004).

[18] Williams R.J. \& Martinez N.D. Stabilization of chaotic and non-permanent food-web dynamics. The European Physical Journal B - Condensed Matter and Complex Systems.38, 297-303 
(2004).

[19]Brose U. Complex food webs prevent competitive exclusion among producer species. Proceedings of the Royal Society B: Biological Sciences.275, 2507-2514 (2008).

[20] Brose U., Williams R.J. \& Martinez N.D. Allometric scaling enhances stability in complex food webs. EcolLett.9, 1228-1236 (2006).

[21] Brose U., Berlow E.L. \& Martinez N.D. Scaling up keystone effects from simple to complex ecological networks.EcolLett.8, 1317-1325 (2005).

[22]Holling C. The components of predation as revealed by a study of small mammal predation of the European Pine Sawfly.The Canadian Entomologist.91,293-320(1959).

[23]Peter C De Ruiter V.W.J.C. Dynamic Food Webs:Multispecies Assemblages, Ecosystem Development and Environmental Change. Elsevier/Academic Press(2006).

[24]Savage V.M., Gillooly J.F., Woodruff W.H., West G.B., Allen A.P., Enquist B.J. \& Brown J.H. The predominance of quarter-power scaling in biology.Funct Ecol. 18, 257-282 (2004).

[25]Oksanen L., Fretwell S.D., Arruda J. \&NiemelP..Exploitation ecosystems in gradients of primary productivity.The American Naturalist.118, 240-261(1981).

[26]Fretwell S.D. The regulation of plant communities by food chains exploiting them. PerspectBiol Med. 20,85(1977).

[27]Holt R.D. Predation, apparent competition, and the structure of prey communities. TheorPopul Biol. 12, 197-229(1977). 